\title{
High-resolution WRF simulation of fire weather associated with the Mt Cook Station fire
}

\author{
$\underline{\text { Colin Simpson }}^{\mathrm{a}, \mathrm{b}}$, Grant Pearce $^{\mathrm{c}}$ and Veronica Clifford ${ }^{\mathrm{c}}$ \\ ${ }^{a}$ School of Physical, Environmental and Mathematical Sciences, University of New South Wales at \\ Canberra, Canberra, Australia \\ ${ }^{b}$ Centre for Atmospheric Research, University of Canterbury, Christchurch, New Zealand \\ ${ }^{c}$ Rural Fire Research Group, Scion, Christchurch, New Zealand \\ Email: c.simpson@adfa.edu.au
}

\begin{abstract}
The Mt Cook Station fire was ignited in 100\% cured grass by a chainsaw on 16 January 2008. The fire was eventually controlled on 22 January, although mop-up of hot spots continued for several weeks. The fire burned 756 hectares, predominantly in dense stands of wilding conifers and light scrub, making it the largest wildland fire in the South Canterbury Rural Fire District for over a decade. Periods of high intensity fire behaviour were observed during the main fire runs in the dense wilding stands in the $24 \mathrm{hr}$ period following ignition.

The fire weather conditions and synoptic to mesoscale atmospheric processes associated with the Mt Cook Station fire have been examined using weather station data and the Weather Research and Forecasting (WRF) numerical weather prediction (NWP) model. The WRF model was chosen as it is well suited to mesoscale modelling and was nested down to a horizontal grid spacing of $1 \mathrm{~km}$ in the inner model domain.

The WRF model results suggest that northwesterly foehn winds, which are a fairly common meteorological feature of the South Island of New Zealand, were topographically channelled down the alpine basin encompassing the fire early on 17 January. The most intense period of fire behaviour, observed at 0530 NZST on 17 January, occurred during the approximately six-hour period when these foehn winds were at their strongest as they descended the leeward slope of the Southern Alps. The WRF modelled winds are in general agreement with observational reports of the wind conditions noted by firefighters at the scene of the fire. However, the wind conditions at the fire's location were considerably different than at Tekapo RAWS, despite being located only $20 \mathrm{~km}$ apart.

Verification statistics were calculated for the WRF model results through direct comparison with observational data taken from Tekapo RAWS. WRF was able to accurately reproduce the observed air temperatures and relative humidity, but not the wind conditions and Fire Weather Index. Although inaccurate modelling of wind conditions in rugged terrain is a widely accepted issue, it is less well known how this affects fire weather indices derived partially from the wind speed. The results presented in this study indicate that there can be considerable errors in using both NWP model output and nearby weather station data when attempting to understand fire weather conditions in rugged terrain.
\end{abstract}

Keywords: Numerical weather prediction modelling, fire weather, wildland fire behaviour, New Zealand 


\section{INTRODUCTION}

The Mt Cook Station fire was ignited in $100 \%$ cured grass through contact with the hot exhaust of a chainsaw between 1520 and 1530 New Zealand Standard Time (NZST) on 16 January 2008 (Clifford and Pearce 2009). Over the following two days the fire exhibited periods of high intensity fire behaviour while burning in dense stands of wilding conifers, which are an invasive tree species in the high country of New Zealand. A change in the fire weather conditions and a transition to less dense fuels allowed the fire to be contained on 18 January. The fire was declared controlled on 22 January, although mop-up of the remaining hot spots continued for several weeks. The fire burned 756 hectares of wilding conifers and light scrub in the Mackenzie District of the South Island of New Zealand, making it the largest wildland fire in the South Canterbury rural fire district for over a decade.

Clifford and Pearce (2009) provided a fairly detailed description of the fire's behaviour and local fire environment conditions, although they presented only a cursory examination of the fire weather conditions. They relied upon observational weather station data taken from a nearby fire weather station and rain gauge. However, due to the complex terrain in the region surrounding the fire, with high relief terrain directly to the west, north and northeast of the fire, it is unclear if those observational data sufficiently represented the true fire weather conditions at the fire's location.

The primary aim of this study is to extend the fire weather analysis presented by Clifford and Pearce (2009) through the use of high-resolution numerical weather prediction (NWP) modelling. NWP modelling is widely used in wildland fire research and operational fire management to supplement weather station data and improve our understanding of atmospheric processes than can contribute towards high intensity fire behaviour. The fire weather analysis is concentrated particularly on the episode of intense fire behaviour observed at 0530 NZST on 17 January. This study will improve our understanding of the atmospheric processes that can contribute towards extreme fire behaviour in the high country of New Zealand. This study also includes a brief comparison of the NWP model output with weather station data taken from nearby the fire, to provide insights into the model performance and limitations in the rugged terrain of the Southern Alps.

\section{METHODS}

\subsection{Numerical Weather Prediction Model}

The NWP model used in this study is version 3.4 of the Weather Research and Forecasting (WRF) model (Skamarock et al. 2008). WRF was chosen as it is well suited to mesoscale atmospheric modelling, utilises fully compressible non-hydrostatic equations and has a mass-based terrainfollowing coordinate system. The WRF model simulation covers the $72 \mathrm{hr}$ period starting from 1200 NZST on 15 January 2008.

Four model domains with one-way nesting were used to model synoptic and mesoscale atmospheric processes. The model domains had a horizontal grid spacing of 27, 9, 3 and $1 \mathrm{~km}$, respectively, and
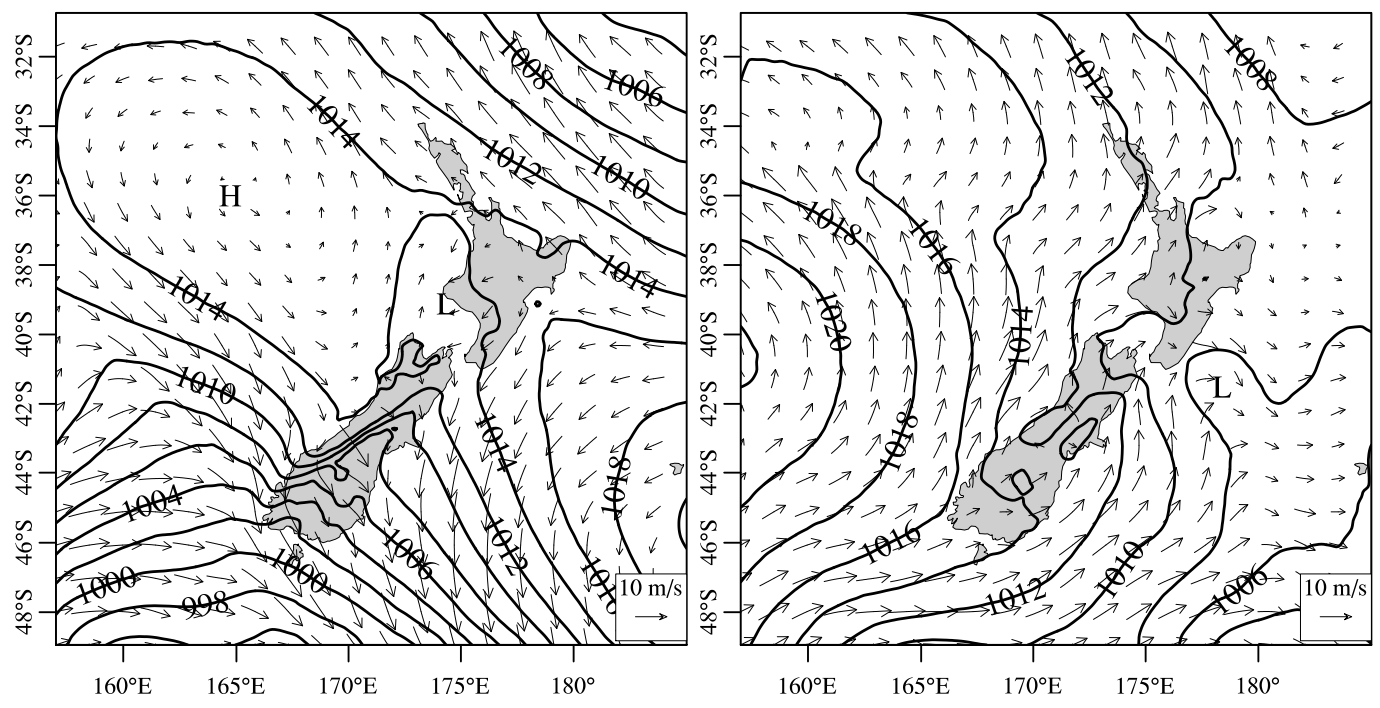

Figure 1. WRF modelled MSLP contours ( $2 \mathrm{hPa}$ interval) and $10 \mathrm{~m}$ horizontal wind vectors $(10 \mathrm{~m}$ $\mathrm{s}^{-1}$ reference vector) at 0000 NZST on (left) 17 January and (right) 18 January. 

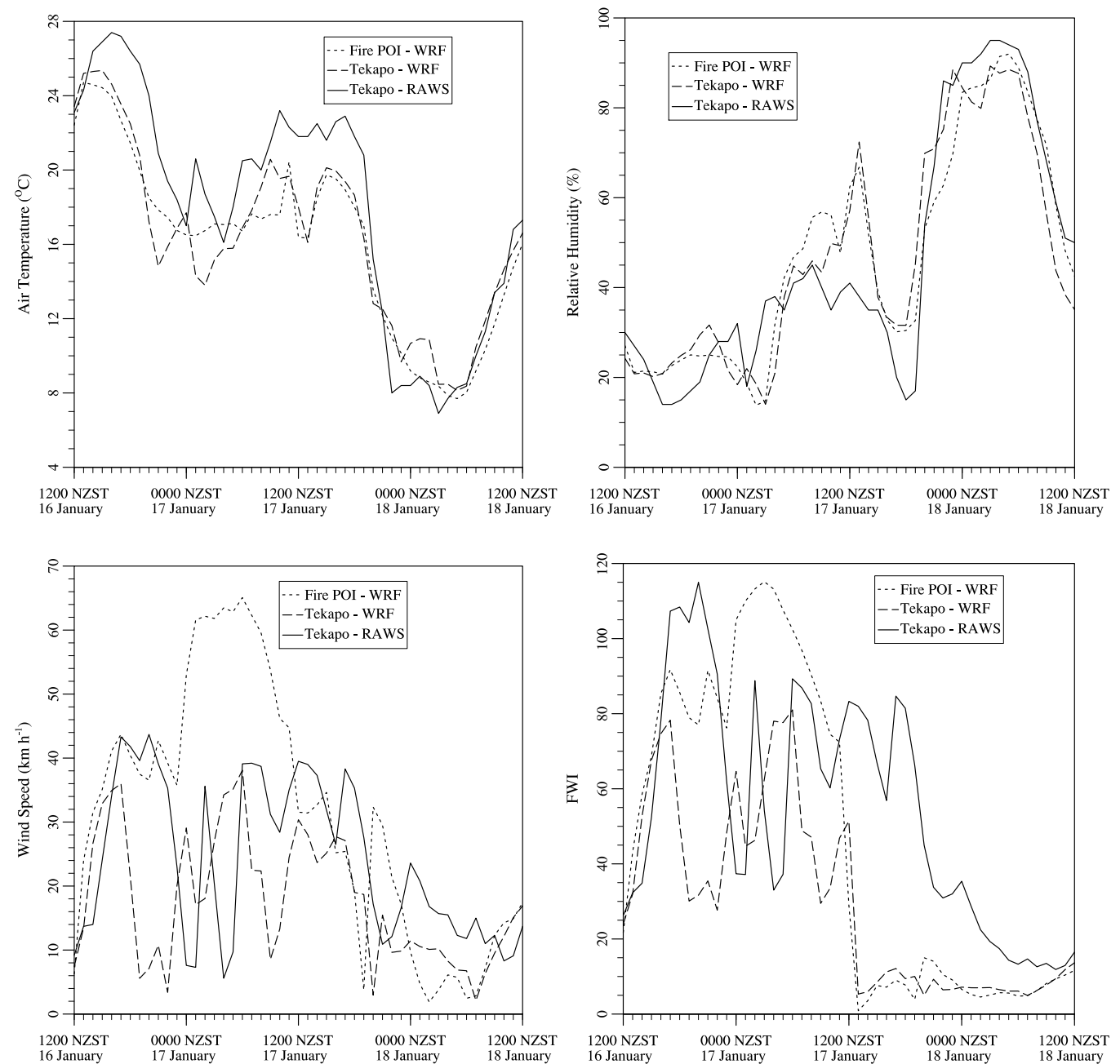

Figure 2. Time series of the modelled and observed hourly (top left) air temperature (top right) relative humidity (bottom left) wind speed and (bottom right) FWI at the site of Tekapo RAWS and the POI.

computational domain of 90x90, 100x100, 100x100 and 148x148 grid points, respectively. The four domains shared an identical configuration of 50 vertical levels, which extend from $27 \mathrm{~m}$ above ground level (AGL) to a fixed model pressure top of $10 \mathrm{hPa}$. The ERA-Interim reanalysis (Dee et al. 2011) was used to provide initial conditions and to nudge the outer model domain at six-hourly intervals.

The microphysics were represented by a single-moment six-class scheme with mixed-phase processes. The sub-grid scale effects of convective or shallow clouds were modelled in the first and second domains using a modified Kain-Fritsch scheme. The surface layer and planetary boundary layer were represented by the Eta schemes. The heat and moisture fluxes over land were provided by the Noah Land Surface Model, which has soil temperature and moisture in four layers, fractional snow cover and frozen soil physics. The short-wave and long-wave radiation physics were represented by a simple short-wave radiation scheme and the Rapid Radiative Transfer Model. A gravity wave damping layer was used in the top $5 \mathrm{~km}$ to prevent reflection of gravity wave energy off the upper boundary.

\subsection{Weather Station Data}

Six weather stations are located within $40 \mathrm{~km}$ of the fire's point of ignition (POI). These include three fire weather stations operated by the National Rural Fire Authority (NRFA), two rain gauges and one electronic weather station operated by the National Institute of Water and Atmospheric Research (NIWA). Clifford and Pearce (2009) argued that the combined Tekapo remote automatic weather station (Tekapo RAWS) and Braemar rain gauge most accurately represented the fire weather conditions at the POI. The combined weather station data at Tekapo RAWS and Braemar includes hourly measurements of the air temperature and relative humidity at $2 \mathrm{~m}$ AGL, wind speed and 

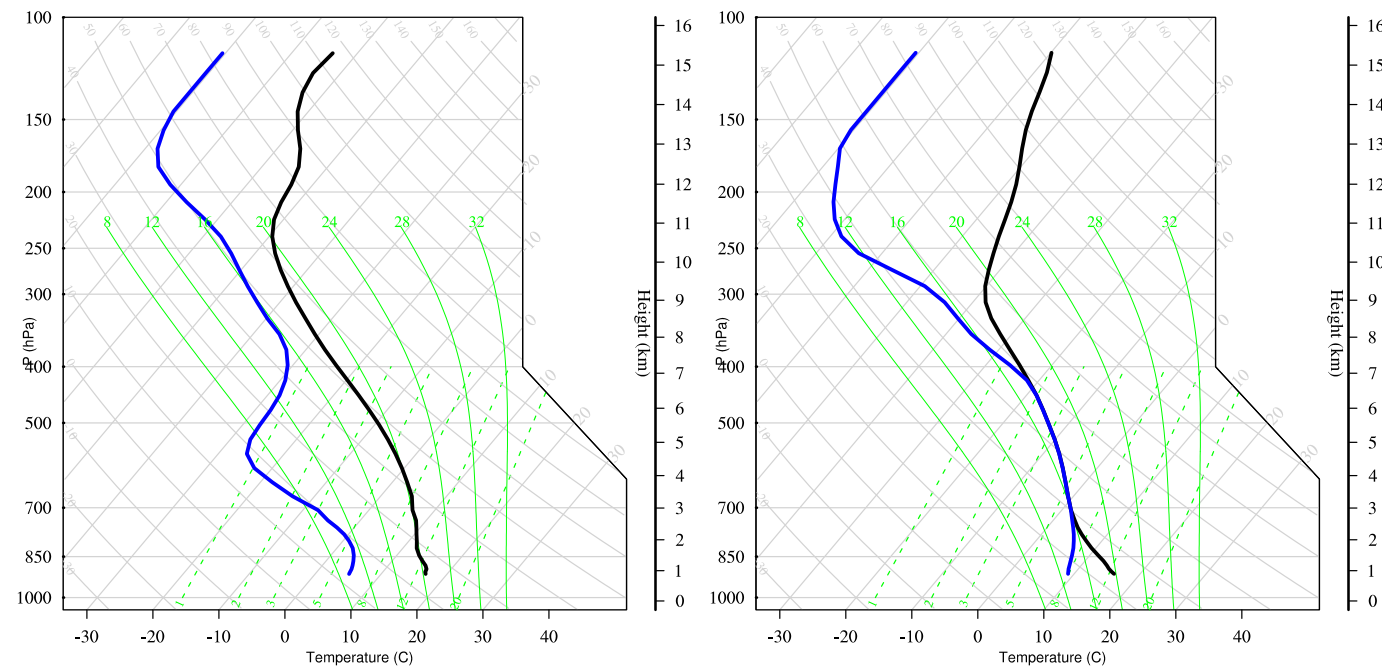

Figure 3. Skew-T Log-P diagrams based on WRF model results at the POI at (left) 0600 NZST and (right) 1200 NZST on 17 January.

direction at $10 \mathrm{~m}$ AGL, and rainfall. No measurements of the upper-air conditions are available in the Mackenzie District for this time period.

\subsection{Fire Weather Assessment}

The fire weather is assessed through consideration of individual fire weather variables and the New Zealand version of the Fire Weather Index (FWI) (VanWagner 1987; Lawson and Armitage 2008). The FWI is a fire behaviour index that quantifies the expected fire intensity for a reference fuel type and is the primary fire weather assessment tool used in New Zealand (Anderson 2005). The FWI is calculated alongside the Fine Fuel Moisture Code (FFMC), Duff Moisture Code (DMC) and Drought Code (DC), which are fuel moisture indices that quantify the short and long-term impact of rainfall on the fuel
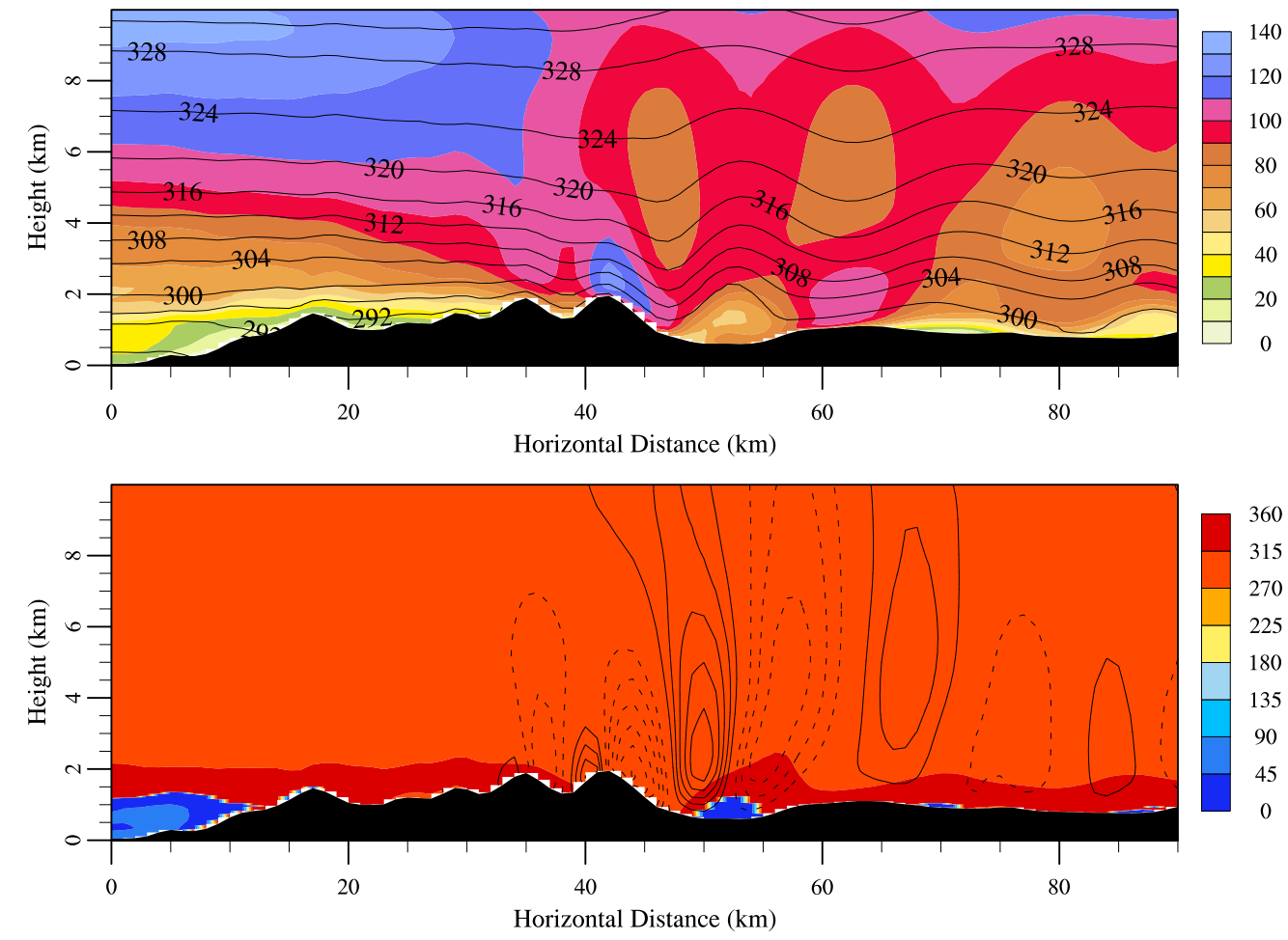

Figure 4. Vertical cross-sections of the WRF modelled (top) wind speed ( $\mathrm{km} \mathrm{h}^{-1}$ ) and potential temperature (contour line interval of $4 \mathrm{~K}$ ) and (bottom) wind direction (degrees) and vertical wind velocity (contour line interval of $5 \mathrm{~km} \mathrm{~h}^{-1}$, dashed lines indicate negative vertical velocity). 


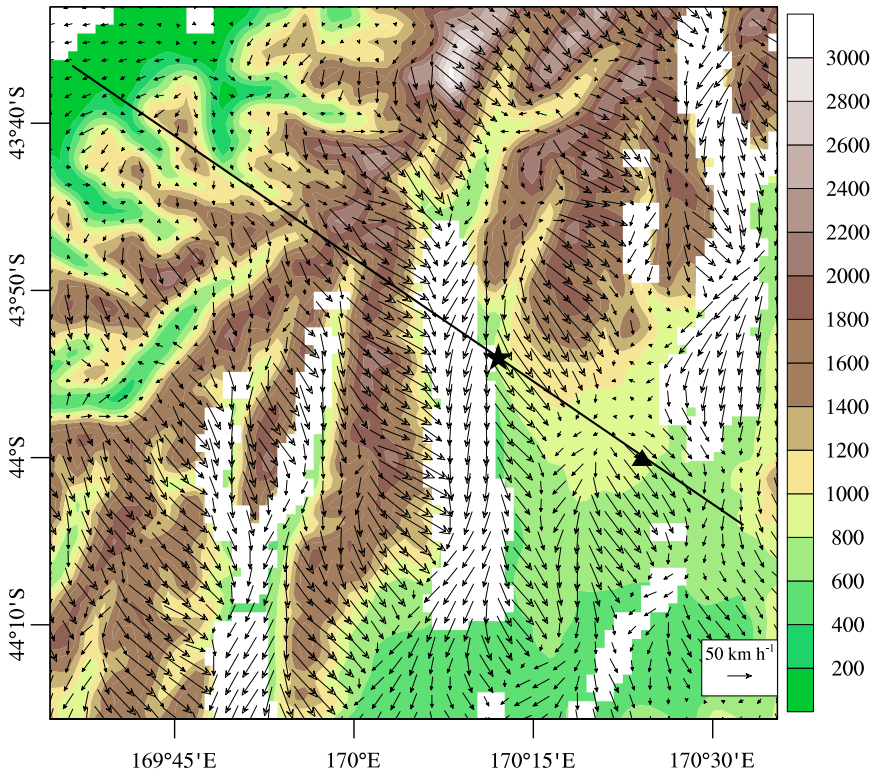

Figure 5. Surface elevation (colour shaded, white represents inland or ocean water land use in the WRF model) and $10 \mathrm{~m}$ horizontal wind vectors at 0600 NZST on 17 January. The black line, star and triangle represent the locations of the vertical cross-section (Figure 4), POI and Tekapo RAWS. moisture content of fine, moderate and heavy fuels and organic layers. An FWI value of 32 or higher generally corresponds to an Extreme fire danger classification for forested regions in New Zealand (Alexander 2008).

\section{RESULTS AND DISCUSSION}

A prolonged dry period in the $\mathrm{Mt}$ Cook region from October 2007 to January 2008 resulted in high FFMC, DMC and DC values of 93.2, 100 and 424, respectively, on 15 January at the combined Tekapo RAWS and Braemar stations. This indicates that fine fuels were very dry with a high ignition probability, and that soil organic layers and moderate to large sized fuels were also dry. These low fuel moisture conditions persisted until moderate to heavy rainfall on 22 and 23 January allowed the fire to

be brought under control.

On 16 January a northwesterly foehn wind, known locally as the Canterbury Nor'wester, developed

Table 1. Verification statistics calculated at Tekapo RAWS for hourly fire weather conditions during the $48 \mathrm{hr}$ period starting 1200 NZST on 16 January. The statistics include the mean observed value $(\mathrm{O})$, mean modelled value $(\mathrm{M})$, standard deviation of observed values $\left(\mathrm{S}_{\mathrm{O}}\right)$, standard deviation of modelled values $\left(\mathrm{S}_{\mathrm{M}}\right)$, mean bias error (MBE), mean absolute error (MAE) and index of agreement (IOA) (Wilmott 1981). D01 is the outer model domain (27 km horizontal grid spacing) and D04 is the innermost model domain (1 km horizontal grid spacing).

\begin{tabular}{|c|c|c|c|c|c|c|c|c|}
\hline Variable & Domain & $\mathrm{O}$ & $\mathrm{M}$ & $\mathrm{S}_{\mathrm{O}}$ & $\mathrm{S}_{\mathrm{M}}$ & MBE & MAE & IOA \\
\hline \multirow{4}{*}{$\begin{array}{l}\text { Air } \\
\text { Temperature }\end{array}$} & D01 & \multirow[t]{4}{*}{18.1} & 14.5 & \multirow[t]{4}{*}{6.1} & 5.2 & -3.6 & 3.6 & 0.88 \\
\hline & D02 & & 15.4 & & 4.7 & -2.7 & 3.2 & 0.89 \\
\hline & D03 & & 16.1 & & 4.7 & -2.0 & 2.6 & 0.92 \\
\hline & D04 & & 16.4 & & 4.7 & -1.7 & 2.4 & 0.93 \\
\hline \multirow{4}{*}{$\begin{array}{l}\text { Relative } \\
\text { Humidity }\end{array}$} & D01 & \multirow[t]{4}{*}{46.0} & 54.9 & \multirow[t]{4}{*}{26.7} & 22.9 & 8.9 & 13.6 & 0.89 \\
\hline & D02 & & 54.9 & & 23.0 & 8.9 & 10.5 & 0.93 \\
\hline & D03 & & 48.2 & & 22.3 & 2.2 & 10.9 & 0.93 \\
\hline & D04 & & 46.7 & & 23.9 & 0.7 & 9.5 & 0.94 \\
\hline \multirow{4}{*}{$\begin{array}{l}\text { Wind } \\
\text { Speed }\end{array}$} & D01 & \multirow[t]{4}{*}{24.0} & 28.5 & \multirow[t]{4}{*}{12.1} & 19.0 & 4.5 & 13.3 & 0.66 \\
\hline & D02 & & 19.6 & & 10.1 & -4.4 & 9.9 & 0.68 \\
\hline & D03 & & 19.3 & & 10.3 & -4.7 & 11.3 & 0.60 \\
\hline & D04 & & 17.8 & & 10.0 & -6.2 & 11.6 & 0.57 \\
\hline \multirow[t]{4}{*}{ FWI } & D01 & \multirow[t]{4}{*}{53.7} & 45.3 & \multirow[t]{4}{*}{31.1} & 33.9 & -8.4 & 23.6 & 0.77 \\
\hline & D02 & & 30.9 & & 18.3 & -22.8 & 25.8 & 0.64 \\
\hline & D03 & & 32.0 & & 25.6 & -21.7 & 30.3 & 0.62 \\
\hline & D04 & & 29.7 & & 24.8 & -24.0 & 30.6 & 0.61 \\
\hline
\end{tabular}


across the southern half of the South Island in response to the synoptic pressure situation shown in Figure 1. A northeasterly barrier flow developed upwind of the Southern Alps, indicating orographic blocking of the lower-level synoptic northwesterly flow. On 17 January a cold front passed over the South Island from the southwest, advancing offshore several hours ahead of the front's progression over land. Rainfall associated with the cold front was measured along the west coast of the South Island, although there was no observed rainfall further inland at Tekapo or Braemar.

The fire weather conditions, particularly the wind speed and FWI, were highly variable in the Lake Pukaki region on 16 and 17 January, as shown in Figure 2. Verification statistics were calculated at Tekapo RAWS using WRF model results from the nearest-neighbour model grid cells and are presented in Table 1. They demonstrate a fairly close agreement between the modelled and observed air temperature and relative humidity, with steady improvement in the mean bias error (MBE), mean absolute error (MAE) and index of agreement (IOA) with increasing spatial resolution. In contrast, there are considerable model errors for the wind speed and FWI in each model domain. The underprediction of the FWI by WRF can be partly attributed to rainfall modelled in the Mt Cook region during the cold front passage at 1200 NZST on 17 January.

Between 2300 NZST on 16 January and 1000 NZST on 17 January, the modelled wind speed and FWI were considerably higher at the POI than at Tekapo RAWS. Modelled wind speeds exceeding $60 \mathrm{~km} \mathrm{~h}^{-}$ ${ }^{1}$ resulted in FWI values exceeding 100 for a number of hours, including during the most intense period of fire behaviour observed at 0530 NZST on 17 January. According to eyewitness accounts, the fire behaviour intensified when the fuel transitioned from light (sparse wildings, grass and low scrub) to heavier slash fuels, from where it jumped across a stream and road into dense wilding stands. This transition in fuel type, which was facilitated and driven by the strong northwesterly winds, led to intense crown fire behaviour in the dense wilding stands (Clifford and Pearce 2009).

Figures 4 and 5 indicate that, at 0600 NZST on 17 January, high-momentum upper-level air was descending on the leeward side of the Southern Alps under stable atmospheric conditions. The lowerlevel air was generally well-mixed below the mountain wave crests, indicating considerable atmospheric turbulence. A change in the $10 \mathrm{~m}$ wind direction within the alpine basins suggests that there was topographic channelling of the lower-level winds over Lake Pukaki. The stable surface layer became destabilised between 0600 and 1200 NZST on 17 January as the cold front approached.

Clifford and Pearce (2009) presented a number of photographs (Figures 5, 6, 11, 29 and 33) that indicated significant tilting of the fire's smoke plume towards the southeast on 17 January. A low-level jet, similar to that seen in several of Byram's blow-up wind profiles (Byram 1954), was modelled at the POI from the time of ignition through to the passage of the cold front over the POI, as seen in Figure 6. The vertical wind profile consisted of high wind speeds, particularly between 0000 and 0600 NZST on 17 January, and adequately explains the tilting of the smoke plume towards the southeast. These high wind speeds, in combination with the atmospheric turbulence under the mountain wave crest, may have contributed towards the extensive downwind spotting discussed by Clifford and Pearce (2009).

\section{SUMMARY AND CONCLUSIONS}

This study has utilised NWP modelling to provide new knowledge on the mesoscale atmospheric processes that contributed towards high intensity fire behaviour observed during the 2008 Mt Cook Station fire. The combined effect of

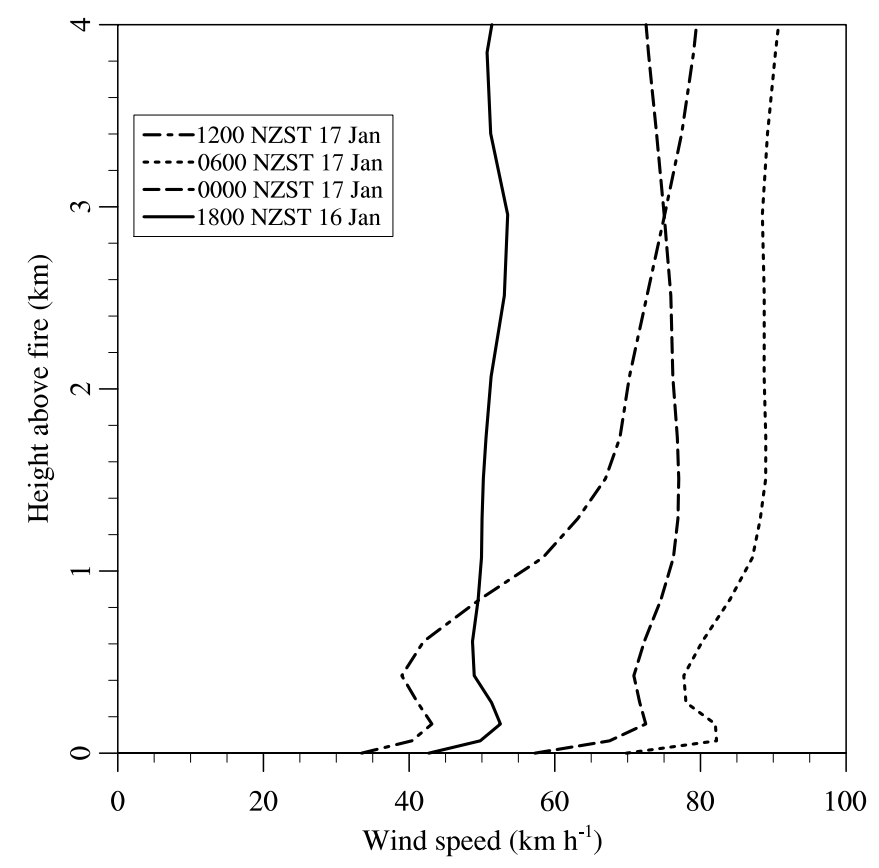

Figure 6. WRF modelled vertical wind profiles at the POI. 
topographically chanelled foehn winds in the direct lee of the Southern Alps, which contained a lowlevel jet in the vertical wind profile and also resulted in mountain wave activity, and a transition of the fire from scrub to dense stands of wilding conifers appears to have contributed towards this high intensity fire behaviour.

There were considerable differences between the WRF modelled wind conditions and FWI at the POI and Tekapo RAWS, despite being located only $20 \mathrm{~km}$ apart. Clifford and Pearce (2009) may therefore have considerably underestimated the wind speeds present at the fire during the principle episode of extreme fire behaviour at 0530 NZST on 17 January by using data from Tekapo RAWS. This raises concerns over the ability of fire weather conditions to be known accurately in the rugged terrain of New Zealand's high country without the aid of high-resolution NWP model forecasts and in-situ fire weather measurements.

This and other case studies of significant wildland fires provide an excellent opportunity for investigating how NWP modelling can improve understanding of mesoscale atmospheric processes that contribute towards extreme fire behaviour. However, it is now well established that NWP models often have difficulty accurately modelling wind conditions, and therefore also fire weather indices such as the FWI, in the complex terrain of New Zealand (Simpson et al. 2013). This has important implications for the interpretation of NWP forecasts and weather station data by fire management.

\section{ACKNOWLEDGEMENTS}

The weather station data were obtained from NIWA. We acknowledge Andrew Sturman, Peyman Zawar-Reza, Marwan Katurji and Iman Soltanzadeh at the University of Canterbury for useful discussions relating to this study. The WRF model simulation was performed on the BlueFern supercomputing facility.

\section{REFERENCES}

Alexander, M.E. (2008). Proposed revision of fire danger class criteria for forest and rural fire areas in New Zealand. National Rural Fire Authority, Wellington.

Anderson, S. (2005). Forest and rural fire danger rating in New Zealand. Forestry Handbook. New Zealand Institute of Forestry, Christchurch.

Byram, G.M. (1954). Atmospheric conditions related to blowup fires. US Department of Agriculture, Southeastern Forest Experiment Station.

Clifford, V.R. and Pearce, H.G. (2009). Fire behaviour case study: Mt Cook Station fire, 16 January 2008. Scion Report No. 17031. Rural Fire Research Group, Scion, Christchurch.

Dee, D.P., Uppala, S.M., Simmons, A.J., Berrisford, P., Poli, P., Kobayashi, S., Andrae, U., Balmaseda, M.A., Balsamo, G., Bauer, P. et al. (2011). The ERA-Interim reanalysis: Configuration and performance of the data assimilation system. Quarterly Journal of the Royal Meteorological Society, 137.656, 553-597.

Lawson, B.D. and Armitage, O.B. (2008). Weather guide for the Canadian Forest Fire Danger Rating System. Natural Resources Canada, Canadian Forest Service, Edmonton, Alberta, Canada.

Simpson, C. C., Pearce, H. G., Sturman, A. P. and Zawar-Reza, P. (2013). Verification of WRF modelled fire weather in the 2009-10 New Zealand fire season. International Journal of Wildland Fire, Online Early.

Skamarock, W.C., Klemp, J.B., Dudhia, J., Gill, D.O., Barker, D.M., Duda, M.G., Huang, X.Y., Wang, W. and Powers, J.G. (2008). A description of the Advanced Research WRF Version 3. NCAR Technical Note 475. Available at: http://www.mmm.ucar.edu/wrf/users/docs/

Van Wagner, C. E. (1987). Development and structure of the Canadian Forest Fire Weather Index System. Government of Canada, Canadian Forestry Service Technical Report 35, Ottawa, Ontario.

Wilmott, C. J. (1981). On the validation of models. Physical Geography, 2: 184-194. 